day so largely lacks, some relationship to the psychical needs and attitudes of those under instruction. JoHN Dewey.

University of Chicago, February 6, 1896.

\section{DOES THE PRIVATE COLLECTOR MAKE THE BEST} MUSEUM ADMINISTRATOR?

THE concluding portion, section $\mathrm{K}$, of Dr. Goode's recent paper on the Classification of Museums, is devoted to a consideration of private cabinets and collectors, and to the major portion of the propositions therein laid down all can heartily subscribe. There is, however, one among them to which I can not fully assent, at least so far as museums of natural history are concerned, and that is, that "The person who has formed a private collection can most successfully manage one for the use of the public."

It must be confessed that this doubt largely rests upon theory, but an acquaintance with some collectors makes it seem probable that it is, after all, well founded.

A considerable amount of collecting is done with no purpose in view other than that of accumulating specimens, but, on the other hand, a private collection may be formed with a definite purpose and along certain lines. In the one case the collector certainly shows no unusual fitness for a position in a museum, while in the other he is interested in his collection for what he can get out of it himself and not for the benefit it may be to others, and this is exactly the opposite view to that which should be held by an officer in a public museum. This is not saying that such is the point of view universally assumed by museum curators, but it is certain that the success of a public museum depends on the extent to which it is adopted. Again a private collector is, from the nature of the case, apt to be one-sided, to lay too much stress on one group to the exclusion of others, and thus to lack the evenness of balance which should be one of the characteristics of the 'museum man.' This one-sidedness frequently takes the form of undue preference for rare or costly specimens, attaching an undue importance to the specimens themselves rather than what is to be got out of them.

Moreover the care and arrangement of a private study series and of a public study series, and, above all of an exhibition series, are entirely different things and require a totally different treatment. A private series may be illarranged and poorly labeled, but the owner knows each specimen, its history and whereabouts. A public study series should, on the contrary, be so arranged and so labeled that any student may consult it and make notes upon it, while in an exhibition series the specimens should be so chosen that, while each conveys some information, all form a harmonious whole.

A private collector may know his own needs, but he would not know or would not care for the needs of the public, and he would carry to a public museum the taste for accumulation, or for research, which probably led to the formation of his own collection. Accumulation is a good thing, but it needs to be properly directed in order to be of public service, while there is probably no greater drawback to the public efficiency of a museum officer than too great devotion to original research, as this leads not only to lack of care for material which has served its turn, but to a very decided lack of interest in the public which must be reached through the exhibition series.

This criticism is by no means to be construed into a criticism of the private collector; the value of his work and the influence of his collections are immense; it is simply a denial of the proposition that because a man has formed a private cabinet he is therefore best fitted to administer a public museum.

WAshington, D. C.

F. A. LuCAs.

\section{SCIENTIFIC LITERATURE.}

\section{Lehrbuch der Entwicklungsgeschichte des Mensch-} en und der Wirbelthiere. OsCAR HeRTwig.

Jena, Gustav Fischer. 1895. Pp. xvi +612 . This excellent work now appears in a fifth edition, in which many improvements have been made. Prof. Hertwig is especially distinguished both for his comprehension of the problems of morphology and for the lucidity of his explanations, so that his text-book has long been accepted as a valuable treatise both for students and for advanced workers, and has been accorded the distinction of translation into several languages. A very admirable 